\title{
Exploring Teachers' Experiences of Participating in Teacher Inquiry as Professional Learning
}

\author{
Eleanor Gillis and Jennifer Mitton-Kükner
}

St. Francis Xavier University

\section{Authors' Note}

Eleanor Gillis may be contacted at Eleanor Gillis x2015jvh@,stfx.ca and Jennifer MittonKükner may be contacted at jmitton@stfx.ca.

\begin{abstract}
Teacher inquiry is the intentional and methodical reflection on one's praxis that leads to action, and the resulting adjustments to one's teaching practice. While scholars identify the importance of supports to be in place to sustain engagement in teacher inquiry, the specifics of the supports have remained somewhat unidentified, and there is little documentation about what teachers experience as they engage in teacher inquiry as part of a school-wide professional learning initiative. This paper explores the experiences of three middle school teachers participating in a year-long, guided teacher inquiry as part of a school's professional learning plans. It is approached from an ethnographic, emic perspective. The challenges and supports teachers experienced when engaging in the inquiry process, as well as what they felt allowed honest dialogue, emerged as important aspects informing the results of this study. Participants identified that feeling safe influenced their ability to engage in teacher inquiry, and their willingness to address challenges associated with conducting research.
\end{abstract}

Keywords: teacher inquiry; teachers as researchers; school-based professional learning 


\section{Exploring Teachers' Experiences of Participating in Teacher Inquiry as Professional Learning}

Teacher inquiry is the intentional and methodical reflection on one's praxis that leads to action, resulting in adjustments to one's teaching practice (Fichtman Dana \& Yendol-Hoppey, 2014; Stenhouse, 1981). Teachers inquiring into the effectiveness of their own practice to improve teaching and learning has been called action research, practitioner research, teacher research, classroom research, collaborative inquiry, critical inquiry, self-study, and teacher inquiry (Esposito \& Smith, 2006; Fichtman Dana \& Yendol-Hoppey, 2014; Roulston, Legette, Deloach, \& Pitman, 2005). This practice has been widely researched, with benefits being identified by multiple authors. For example, scholars have found that teacher inquiry empowers teachers because they are encouraged to be autonomous in their practice (Castle, 2006; Espositio \& Smith, 2006; Lankshear \& Knobel, 2004), and to see it as continuous professional learning designed by their own efforts (Ellis \& Castle, 2010; Hulburt \& Knotts, 2012; Navaneedhan, 2011; Timperley, Parr, \& Bertanees, 2009). Zeichner (2003) argued this process can result in teachers feeling a renewed feeling of professionalism, while others have found teacher inquiry can positively impact classroom instruction and learning (Ermeling, 2009; Jao \& McDougall, 2015) and provide intellectual satisfaction to those who engage in it (Cochran-Smith \& Lytle, 1992).

Teacher inquiry has also been found to help teachers become more reflective (Limbrick, Buchanan, Goodwin, \& Schwarcz, 2010), become more invested in the development of curriculum (Borg, 2010), and become more independent problem solvers (Simon, 2015); all of which may inform beneficial changes to teacher praxis (Harrison, 2013). Because teacher inquiry has also been found to build teacher confidence and to renew excitement for teaching (Zeichner, 2003), it is positioned by many as rewarding professional learning (Timperley et al., 2009).

Conversely, teacher inquiry, like many professional learning initiatives, also faces challenges, such as finding time for the practice to be taken up (Mitton-Kükner, 2015a, 2015b; Zeichner, 2003), and feeling safe to share and collaborate in honest ways about teaching practices (Kelly \& Cherkowski, 2015). While scholars identify the importance of supports (Cooper \& Cowie, 2010) and trust (Hallam, Smith, Hite, Hite, \& Wilcox, 2015) to be in place to sustain engagement in teacher inquiry, the specifics of the supports have remained somewhat unidentified, and there is little documentation about what teachers experience as they engage in teacher inquiry as part of a school-wide professional learning initiative.

The underlying purpose of this ethnographic study was to gain insight into the experiences of middle school teachers experiencing year-long, guided and supported teacher inquiry as professional learning. The exploration was grounded in the following primary question: What are the experiences of middle-school teachers participating in a year-long teacher inquiry as part of a school's professional learning plans? This question had three related subquestions:

1. What supports, if any, benefit teacher researchers?

2. What challenges, if any, do teacher researchers encounter?

3. What, if anything, allows teacher researchers to engage in honest dialogue about inquiry into their personal teaching practice? 
In what follows, we explore the challenges and supports teachers experienced as novice researchers, discussing factors that participants identified as supportive for their engagement in teacher inquiry. Prior to this, we provide an overview of the benefits, criticisms and constraints of teacher inquiry, followed by the theoretical framework and methodological design of the study.

\section{Teacher Inquiry: Benefits, Criticisms, and Constraints}

Teacher inquiry can be a means of fostering understanding of teaching practices and pedagogy (Ellis \& Castle, 2010; Hulburt \& Knotts, 2012; Navaneedhan, 2011; Timperley et al., 2009) with the potential of informing long-term professional learning in how results may be shared amongst teachers within school contexts as way to build local knowledge (Lytle \& Cochran-Smith, 1992; Zeichner, 2003). Scholars note the benefits of teacher inquiry in that it has been found to inform instructional improvements (Ermeling, 2009; Jao \& McDougall, 2015; Limbrick et al., 2010) that are cyclic, continuous (Ellis \& Castle, 2010; Navaneedhan, 2011), and learner-centered (Zeichner, 2003). This is especially true when teacher inquiries are based on student need (Timperley et al., 2009). In addition, some scholars connect the potential of teacher inquiry to the understanding of other practices currently popular in the teaching profession, including differentiated instruction, response to intervention (Fichtman Dana \& Yendol-Hoppey, 2014), data-driven decision making (Fichtman Dana \& Yendol-Hoppey, 2014; Simon, 2015), professional learning communities (Birenbaum, Kimron, \& Shilton, 2011; Birenbaum, Kimron, Shilton, \& Shahaf-Barzilay, 2009; Cooper \& Cowie, 2010), and teacher professional growth (Latta \& Kim, 2010; Limbrick et al., 2010).

Scholars also argue that ongoing teacher inquiry can lead to educational reform by aligning research, teacher practice, and student learning so the changes taking place are based on students and their learning in the classroom setting (Cochran-Smith \& Boston College Evidence Team, 2009; Cochran-Smith \& Lytle, 1992; Darling-Hammond \& McLaughlin, 1995). The research indicates that conducting research benefits seasoned teachers (Borg, 2010; Butt \& Shams, 2013;) by fostering a renewed sense of professionalism (Timperley et al., 2009) and autonomy of practice (Castle, 2006). While the benefits to teacher inquiry seem substantial, it is not without its criticisms or challenges.

Traditionally, educational research has been conducted by academics from outside of school settings. The credibility of teacher inquiry is often challenged due to the assumption of bias in the study of one's own teaching practices (Stenhouse, 1981). Some scholars argue that the evidence gathered is without rigor and questionable in how it is analyzed (Borg, 2010). This statement has grounds because teachers are most often not trained as researchers (Stenhouse, 1981). Borg (2010) proposed that the use of a systematic process of collaboration and rigor is well-suited to enhancing the validity associated with teacher inquiry. Even with these considerations, scholars concede that teacher inquiry is different from formalized academic research and does not necessarily align with university research and its culture (Cochran-Smith \& Lytle, 2009).

Compounding the criticisms against teacher inquiry are the everyday constraints that limit teachers from engaging in ongoing research of their practice. Scholars note how a lack of time is a recurring factor that limits teacher engagement in research inquiry (Cochran-Smith \& Boston College Evidence Team, 2009; Cochran-Smith \& Lytle, 1992; Stenhouse, 1981; 
Zeichner, 2003;). Many authors write about the potentiality that exists with teacher inquiry, but the complexity of the teaching profession does not necessarily provide enough time for teachers to engage in the inquiry process (Mitton-Kükner, 2013, 2014, 2015a, 2015b). Sufficient time for an in-depth look at one's practice is important, if teacher inquiry is to be effective (Zeichner, 2003).

\section{Theoretical Framework}

To better understand the experiences of teachers as they engaged in inquiry, three interrelated notions were drawn upon as data was collected and analyzed throughout the study: Constructivism (Applefield, Huber, \& Moallem, 2001), cognitive dissonance (Patton, Parker, \& Neutzling, 2012), and inquiry as stance (Cochran-Smith \& Lytle, 2009). Constructivism, as a theory of learning, fostered our understanding of teacher participants' experiences from a cultural, situated viewpoint (Applefield et al., 2001), and was well-suited to the focus, design, and analysis of an ethnographic approach. As our primary focus was upon participants' research experiences, how they constructed meaning about the inquiry process, and how their understanding informed their classroom practices, a constructivist worldview enabled us to consider the participants as active creators of their own understanding. Engaging participants in interviews over the course of our research study, as they themselves engaged in research, was an important constructivist element underlying the design of the study because it enabled participants to reflect upon their experiences and make sense of what was being learned. Furthermore, constructivist learning theory enabled us to identify what collaborative supports ensured teacher participants engaged in the professional learning, by considering what they emphasized in ongoing ways.

Also conceptually informing the study was the understanding that teacher inquiry aims to push teachers into a place of cognitive dissonance, so they see the need to make incremental changes to their practices (Patton et al., 2012). This kind of learning is an active process because it requires teachers to assess an aspect of their practice to decide what needs to be done in attempt to improve. With this in mind, it was important to establish trust throughout the study; participants needed to feel comfortable to openly and honestly engage in disequilibrium for the purpose of learning (Nelson, Deuel, Slavit, \& Kennedy, 2010).

Finally, the notion, inquiry as stance (Cochran-Smith \& Lytle, 2009) was a critical idea honing our thinking about participants' experiences. Cochran-Smith and Lytle (2009) described inquiry as stance as a holistic way of approaching the profession of teaching, through continuously experimenting with and inquiring into pedagogy, resulting in the "blurring of theory and practice" (p. 3). This idea is rooted in the phenomenon the study aimed to understand, that is, exploring how teacher inquiry may be sustained and embedded as a professional learning practice as a means to build local and relevant knowledge (Cochran-Smith \& Lytle, 2009). This shift is only possible when teachers are trusted to determine their professional learning needs, rather than being told their professional learning needs (Lytle \& Cochran-Smith, 1992). While the scope of this study is limited, attention was paid to whether the practice of teacher inquiry spread beyond what individual teachers identified as changes to their own practice.

\section{Methodology and Methods}

Qualitative research aims to construct understanding by exploring how others have attributed meaning to their experiences (Merriam \& Tisdell, 2016). Because this study aimed to explore the 
experiences of teachers engaging in professional learning around teacher inquiry, an inductive qualitative process (Merriam \& Tisdell, 2016) exploring this phenomenon was well-suited to the study. Qualitative research also utilizes the researcher as the main source for data collection through richly descriptive data (Geertz, 1973; Merriam \& Tisdell, 2016). Finally, qualitative studies require an inquisitive mindset that embraces ambiguity, careful observation, and an ability to interpret data over time through writing (Merriam \& Tisdell, 2016). Designed as an ethnography (Hammersley, 2006; Yon, 2003) that considered the entire teacher population participating in professional learning at Eleanor's school, the study was focused on an in-depth look at the practices of three teachers. Eleanor's immersion at the site created an opportunity for a thorough look at the interactions amongst people, their interactions with outsiders, their habits, and the language used within the culture of the school (Hammersley, 2006). As a teacher in this school, Eleanor also participated in the teacher inquiry and had established relationships with the teachers who took part. While the experiences reported are not generalizable, they may provide insights for others situated in similar school settings (LeCompte \& Goetz, 1982).

The study took place in the spring of 2017 in an urban Canadian middle-school in a western province of approximately 750 students and 30 teachers. All of the teachers on staff participated in year-long teacher inquiries as part of the school's professional learning series. In the school, formative assessment and professional learning communities were ongoing expectations and teachers were viewed as designers of learning experiences through continuous curriculum development based on provincial programs of study.

For the year-long professional learning series in the school, teachers were responsible for intentional reflection on their practice, collaborating on what had been done, and gathering and analyzing data as they tried out something new in their classrooms. Three teacher participants, Jade, Morgan and Elijah, ${ }^{1}$ took part in the study between the months of March and May, 2017. While the teacher participants were not followed for the duration of the year-long professional learning series, they were asked questions about their experiences that were based on the entire school year. At the time of the study, Jade and Morgan had been teaching for approximately ten years, and Elijah was in his third year of teaching. Participants volunteered for the study and were full-time teachers with whom Eleanor had established working relationships. They were diverse in their pedagogy, personal experiences, and backgrounds.

\section{Data Collection}

The data collected for this study consisted of interviews, teacher generated artifacts representing the personal inquiries of teachers who participated in the study and in in-school observations. This triangulation of data from interviews, observations, and artifacts allowed for comparison and inferencing of commonalities (Hammersley, 2006; LeCompte \& Goetz, 1982; Merriam \& Tisdell, 2016; Pierides, 2010).

\section{Interviews}

Teacher participants were interviewed three times in 2017, once in March, and twice in May (beginning and end of the month). Interviews were semi-structured (Merriam \& Tisdell, 2016) and individually conducted. Merriam and Tisdell (2016) emphasize that a semi-structured interview allows the researcher to acknowledge the ways in which participants define their world in unique ways, and while important issues are to be discussed, the wording of questions are flexible and live in response to the conversation and relationship between participant and 
researcher. A semi-structured interview provided flexibility and opportunity for unexpected dialogue during the interviews. The March interviews established a baseline of understanding regarding participants' teacher inquiry experiences. Final interviews took place after teacher inquiries had concluded, which provided opportunity for the whole process to be described, and to allow for participants to note any change or growth in their teaching practices.

\section{Artifacts}

Personal artifacts from teacher participants' inquiries were the second data source. Since the study explored the experiences of teachers participating in year-long teacher inquiry work, the ongoing artifacts they generated for their inquiries were readily available for mining (Merriam \& Tisdell, 2016; Wilson \& Chaddha, 2010). Participant artifacts consisted of the teacher professional growth plans as maintained online. In these online workspaces, teachers self-identified a goal in October, and then reflected on their progress towards this goal by looking at the evidence of student learning that resulted from adjustments to their teaching practices. Updates on their progress were documented on their online workspaces in February and May, creating a total of nine participant entries. While this documentation did not divulge much regarding the experiences of teachers, which was the focus of the study, digital documentation did act as a verification of what teachers described as their successes and struggles with the teacher inquiry process.

\section{Observations}

Given the research problem and the ethnographic nature of the study, observation was a useful part of the data collection. Participant observation is central to the methodology of an ethnography (Hammersley, 2006) because ethnographies are rooted in immersion in the culture (Delamont \& Atkinson, 1980) for descriptive observation and interpretation. Over the threemonth period there were a total of 27 entries in which teacher responses to the teacher inquiry process were documented by Eleanor; particular attention was paid to what supported participants' efforts to engage in the teacher inquiry process, and the constraints they also experienced.

\section{Data Analysis}

Important to the data analysis process of this study were the efforts made to inductively analyze data as it was collected. Inductive analysis is an important aspect of qualitative research in that the timing and integration of analysis with ongoing data collection methods and decision making processes distinguishes it from traditional, positivistic research (Merriam \& Tisdell, 2016).

Open codes played a significant role, as data was sifted through and notes were maintained about information that could be significant (Merriam \& Tisdell, 2016). Open codes were identified between each set of interviews, by underlining and circling words that indicated recurring patterns across interviews and field notes. By grouping open codes together based on identified commonalities, axial codes, or themes, emerged during latter interpretation stages (Merriam \& Tisdell, 2016). When open coding of initial data was underway, axial codes were formed, which created categories that acknowledged themes in the data by providing titles that inferred and united the open codes. These axial codes were created with consideration of context, what was understood and believed to be true about each of the participants, and the observational data. Inductive analysis that took place between the first and second interviews, as well as 
between the second and third interviews, influenced the second and third sets of interview questions respectively. In both cases, additional questions were developed as a result of coding, to solicit further detail about the data that was being generated. In addition, inclusion of "devil's advocate" questions (Merriam \& Tisdell, 2016) in the final interview acted as a form of member check to ensure that the ideas participants identified were being interpreted in the way they had intended.

\section{Findings: The Importance of School Leaders and Colleagues in Fostering Teacher Inquiry}

Overall, participants felt they developed their practice regardless of whether there was a schoolwide teacher inquiry initiative or not. Participants believed in the importance of continuously inquiring into their practices and growing as professionals. Sharing the results of their ongoing inquiries with others, however, was identified as dependent upon an environment that fostered such participation. All participants felt that fostering authentic engagement in the inquiry process required someone to lead the process. They also felt that if leaders were honest in sharing their successes and failures, those wary of the teacher inquiry process could learn from a leader's example. This kind of leadership, they felt, might set an example for other teachers, creating a sense of safety since someone was adopting the idea first. Leading by example, participants explained, had the potential to show other teachers that it was okay to take calculated risks within one's practice, make mistakes, and learn from them. This showing of vulnerability, seemingly, for participants, could enhance trust and positively influence teachers to engage in teacher inquiry. When teacher participants felt safe and supported in their practice, they described being more likely to take informed risks within their practice, being more willing to share their results, positive or negative, and being more affable to the idea of engaging in real conversation about how they might adjust their practice for greater success. Participants identified that sharing their teaching practice experiences with their colleagues, combined with the emphasis of ongoing dialogue as part of their teacher inquiries, seemed a key piece of what they did to move their research and learning forward. Participants indicated that they were most comfortable doing this with colleagues whom they felt they could trust. In what follows, the importance of relationships with school leaders and with colleagues will be discussed to demonstrate why participants felt these were critical for sustaining the practice of teacher inquiry.

\section{Theme One: School Leaders' Communication of Expectations and Intent for Teacher Inquiry}

Participants indicated that leaders play an extremely important role in making teacher inquiry possible as an ongoing, shared, school-wide practice. For teacher inquiry as professional learning to become a part of the school culture, participants identified that clear communication of expectations as well as communication of the intention underlying the decision to take up teacher inquiry to the staff was necessary.

As expressed in the first interview, participants had some shared understandings about teacher inquiry, though all described a desire for further clarification from those leading the initiative. For example, Elijah said,

Teacher inquiry [shows] how you are as a teacher, going through the process of your pedagogy, so that you are, in a sense, controlling the direction of where you're going... and being open to the possibilities. Inquiry...is looking for ways of...challenging and putting 
yourself in uncomfortable situations that are going to give you different ways of seeing your practice. (Interview 1, March 22, 2017)

Similarly, Jade said that teacher inquiry was, "identifying my areas for growth, finding strategies and collaborating with others to address those areas for growth, and actually driving my practice and my improvement on my own, with some support if I need it" (Interview 1, March 21, 2017). Like Elijah, she viewed it as an independent process of reflection and growth. When Morgan was asked what teacher inquiry meant to her, she responded by saying, "I think it's similar to student inquiry, it's guiding your own teaching based on... what you're interested in, kind of" (Interview 1, March 23, 2017). Unlike Jade and Elijah, Morgan seemed less confident when asked to define teacher inquiry. Later in that interview, when asked to describe her teacher inquiry experiences thus far in the school year, she provided some insight as to why she might not have been confident in defining teacher inquiry. Morgan explained,

I don't know that it's been outlined... and communicated as well as it could have been. Sometimes when we get together with our PLCs we're like, "okay, what are we really supposed to be doing?" ... I don't know that there's necessarily...been that strong communication of what does it look like and what should we be doing.

Morgan's statements clarify why she might have been confused as she used the terms PLC (professional learning community) and teacher inquiry synonymously. She recognized that she had a muddled understanding when she stated that expectations were not clearly outlined or communicated.

While Jade seemed confident in what teacher inquiry was, she did identify that she would have preferred more structure, similar to Morgan. While Morgan seemed to find that clear expectations were lacking, Jade said she felt that it was the vision that was lacking. Both Jade and Elijah connected the lack of a shared vision to the different messages schools constantly received. Jade stated,

I'm just wondering...the different jargon that comes up through education, and sometimes it's the same concept rephrased or renamed. I just feel like it's so time specific, but when we look at things like assessment, task design, maybe a classroom environment or classroom culture, those to me are more timeless and should be the end goal for schools and boards, as opposed to what's the latest buzz word. (Interview 3, May 30, 2017)

Elijah said, "It also felt as though this process [teacher inquiry] is being used to justify other stakeholders as opposed to the interest of the teacher or the growth of the teacher. And so, it didn't feel genuine" (Interview 3, May 31, 2017). In these statements, both Jade and Elijah connected a lack of clear vision about teacher inquiry to the mixed messages they received from school board directives, many of which, they felt, were disconnected from the daily work of teachers in a school. Further, participants seemed to feel that teacher inquiry was taken up for reasons other than teacher growth and student learning; because of this, they did not feel that genuine engagement was fostered.

\section{Theme Two: School Leaders Need to Foster Honest Dialogue by Sharing their Own Attempts}

Participants felt that an administration and school leadership team who also engaged in the practice of teacher inquiry, aiming to learn and improve in their own roles, had the potential to 
regulate the practice across a school. Teachers might share their personal experiences to a wider audience, participants identified, if they felt safe to make mistakes. If these were the professional learning conditions fostered by the school leadership, participants explained, it could help embed teacher inquiry as part of a school's culture. They felt that feeling safe to make mistakes could be fostered by administration if they also put themselves out there and engaged and reported on their own teacher inquiries. In doing so, participants felt, this might normalize risk-taking and learning from mistakes as part of the teacher inquiry process. For example, in reference to taking risks, Jade felt honest conversation was needed, describing how she saw her own leadership role in the past when she was a teacher learning leader of a group. She said,

As a leader, I put myself out there. I did have comfort [be]cause I was with...grade team partners and I knew them really well. The other two [members] I didn't know as well, but because I had that one or two safe zone[s], it gave me encouragement, plus I think the title of leader, it (almost) forced me; it made me realize that if I don't put myself out there, then other people are not going to feel comfortable. (Interview 3, May 30, 2017)

In her statements, Jade alluded to the idea that beginning the process of teacher inquiry required making one's self vulnerable. She also referenced her personal need to do this with people who she felt safe around. When leaders put themselves out there, Jade explained, they lead by example, and this, in turn, might help to create a safe space for others to take risks.

While the idea of leaders putting themselves out there was recurring with all participants, it seemed to be connected to the need for honest dialogue as part of professional growth. When asked whether honest dialogue was necessary for true growth, Elijah responded by saying, "You can't move unless people are honest" (Interview 3, May 31, 2017). When asked how this might be fostered in a school, he implied that leadership was at the heart of this matter and said, "I think it goes back to that culture of it's not failure, it's just re-adjusting" (Interview 3, May 31, 2017). Here Elijah connected one's ability to honestly inquire into personal practice to one's ability to take risks within their practice. Elijah seemed to feel that when the school culture is one that supported adjustment and the making of mistakes, teachers might be more willing to engage in teacher inquiry.

Likewise, Morgan said she thought, "If you're being a leader and having honest dialogue then other people will want to follow" (Interview 3, May 31, 2017). When asked how honest dialogue could be promoted in a school, she felt, "It needs to be supported somewhat" (Interview 3 , May 31, 2017), though she also recognized that any teacher could promote it. Elijah shared the same sentiment; when asked about how to foster a culture of honesty he said, "It starts from someone stepping up" (Interview 3, May 31, 2017), but he felt that it was best fostered when it came from administration. In an earlier interview he said, "I feel it's creating a culture where everyone recognizes we're all growing in this" and "I think it starts from the top" (Interview 2, May 1, 2017). When asked what he felt the top would need to do, he said "Live it" (Interview 2, May 1, 2017). Like the other participants, Elijah indicated that leadership was important for the teacher inquiry process to be regular and authentic.

Jade also connected the ideas of honesty and learning from experiencing failure. When asked if she felt honest dialogue was necessary for true growth, she said, "We learn more from our mistakes [more] than from our successes, and if you're not honest about where you need to 
grow, then how are you going to get better?" (Interview 3, May 30, 2017). When asked how this could be fostered in a school setting, she said,

[You] lead by example, right? ...like if you're a leader and you're not willing to put yourself out there, then why should other people do it? I think that presence goes a long way. I don't think it's the be-all and end-all, but I think it's a good start. Just because I'm not a leader in the school, doesn't mean I can't take the first step either. But it's hard in a school. I think it does start from the top though. (Interview 3, May 30, 2017)

In this instance, Jade, like Elijah, indicated the leadership in a school needed to live the practice, and lead by example to create a safe space for others to engage in the inquiry process as well. Morgan was also on the same page when it came to the importance of honest dialogue. She said, "If you are not being honest, if you are not discussing where you're at with your teaching, then you're not going to further yourself" (Interview 3, May 31, 2017). This, however, could be a difficult process to engage in, as Elijah indicated that, at times, "I didn't want to look like I didn't know how to do it" (Interview 3, May 31, 2017), in reference to challenges he had with his own teacher inquiry.

\section{Theme Three: School Leaders Influencing Teacher Willingness to Engage in Risk Taking through Teacher Inquiry}

Participants identified the importance of risk-taking as part of professional learning and attributed a willingness to engage in such efforts through their teacher inquiries. They were mindful that taking risks could mean failure but felt if honest dialogue with others was happening, much could be learned. When asked about the role of risk-taking and failure, Morgan said, "I think that you need to kind of think outside the box and put your career and your teaching and your learning first, and take control of that" (Interview 3, May 31, 2017). She also said, "Everything we kind of do is failure, but that's what you learn from. So, if you take a risk and it fails, then you know [learning can still happen]" (Interview 3, May 31, 2017).

When asked about risk taking, Jade stated,

If you don't take risks and own up to mistakes...then how do you know how to improve, right? You really have to put yourself out there to say, "I tried this, this is where I didn't quite meet my own expectations, or this is where I failed"...just even talking through your process, I think you can learn a lot more than just kind of focusing on the positives all the time. (Interview 3, May 30, 2017)

Here, Jade connected the idea of taking risks to failure, and learning from one's mistakes. She also acknowledged the importance of dialogue with colleagues. These ideas seem tied to honest dialogue because, as previously discussed, a feeling of safety is required for teachers to engage in taking risks, making mistakes, and discussing them in an honest way. For the participants, the role of school leaders in creating this kind of safe environment is not to be underestimated.

Finally, Elijah was also in agreement that taking risks and learning from failure were critical components of teacher inquiry. He said, "You can't grow without, like we've been talking about, setbacks. And risks are going into an unknown where you don't know what the outcome is, and that should actually be sought out" (Interview 2, May 31, 2017). For Elijah, when teachers can learn from failure through their practice, they are more likely to improve their practice at an accelerated rate. Again, this idea of taking risks and learning from failure is 
supported when teachers feel safe to do so, as though making a mistake isn't wrong, but rather, encouraged. Participants emphasized that when teachers see leaders practicing this process of risk taking and learning, they are more likely to feel safe to engage in the process as well.

\section{Discussion: The Role of School Leadership in Fostering Positive Conditions for Teacher Inquiry}

All of the participants indicated that feeling safe to inquire into one's teaching practices was best fostered by school administrators and the teacher leadership team. Creating safety for participants meant school leaders had to establish trust through clear communication of expectations as a way of showing their understanding and value of the teacher inquiry process. As described by the participants, a healthy dynamic between school leaders and teachers may be created when they lead by example and engage in this process as well. The presence of participant affect underlies the study's findings. The idea of affect influencing participants' responses to teacher inquiry is reminiscent of the work of Kelly and Cherkowski's (2015), who found that looking after the affective needs of teachers is necessary, so that they can move forward in their professional learning.

Hallam et al. (2015) emphasized the importance of teams of teachers taking the time to work together so trust can be built within a professional learning community. Like Hallam et al. (2015), participants in this study clearly indicated the importance of feeling trusted by the leaders of this process, specifically, their administration. Participants felt that in order to authentically engage in the process of teacher inquiry (i.e. by taking risks and engaging in honest dialogue about their practices), they needed to feel the school leadership viewed them as trustworthy. In addition to the emphasis on trust, participants identified that leaders needed to understand, believe, and practice teacher inquiry themselves, as their actions helped trust to flourish. This seems an important factor informing engagement in the teacher inquiry process, and other scholars have noted similar findings. For example, Nelson et al. (2010) wrote of the importance of teacher leaders facilitating deep conversations in PLCs, while Ermeling (2009) found that instructional improvements are more likely to occur when the teacher inquiry process is led by qualified leaders. Like these researchers, participants in this study also identified that someone qualified needed to lead the process as a way to facilitate quality sharing and conversation, as well as quality personal reflection. The role of the facilitator is a crucial one for teacher inquiry to be adopted effectively, as use of a protocol and time for conversation alone do not guarantee deep and meaningful dialogue (Nelson et al., 2010).

Facilitator beliefs and actions are also closely linked (Patton et al., 2012) to the successful implementation of teacher inquiry. A facilitator, such as a school administrator or a teacher leader, needs to recognize what each participating teacher arrives with, and that learning is an active and social process (Patton et al., 2012). Building trust and credibility is necessary (Patton et al., 2012) for any effective professional learning, especially since learning from failure plays a role in successful teacher inquiry (Simon, 2015), aligning with the findings of this ethnography. Establishing this trust and credibility may aid the facilitator in moving professional dialogue from a place of congeniality ${ }^{2}$ to collegiality, "from sharing to inquiry" so that teacher inquirers "approach conflict as an intellectual challenge rather than an affective or emotional event" and move towards "deeper inquiry and professional learning as opposed to threats to professional identity" (Nelson et al., 2010, pp. 176-177). This effective facilitation of learning requires authentic working relationships based on trust and honesty. Increased trust has the potential to 
allow for more openness with sharing of strategies and student data, by de-privatizing practice (Hallam et al., 2015), and supporting teacher inquiry as professional learning.

Although Cooper and Cowie (2010) identify that sustaining teacher inquiry and PLC. engagement require external support as well as the importance of emotional, social, and intellectual supports, they failed to identify these specific supports. Likewise, Hallam et al. (2015) recognize the importance of trust in effective professional learning communities but continue to question the specifics about how it is developed and the strategies that are used to build it in a school setting. Similarly, how teacher inquiry can be diffused throughout a system, and how assessment to inform decisions can be sustained as an intentional daily practice, remain unknown (Zeichner, 2003).

This study aimed to explore the experiences of middle-school teachers participating in school-wide, mandatory, year-long, guided and supported teacher inquiry, to gain insight into the specifics of what may support or hinder teacher participation in sustaining inquiry as a stance. For the participants of this study, school administration and leadership played an incredibly important role in creating and sustaining the professional learning conditions for teachers to engage in the effort, risks, and honest dialogue needed for their inquiries. This perception of trust seemed connected to how teachers felt, and how teachers felt influenced their engagement in teacher inquiry. This study suggests that sustaining inquiry as stance (Cochran-Smith \& Lytle, 2009) may be supported by school leadership if trust is first established. Participants felt that clearly communicated expectations, an explained vision for the process, and administrators and school leaders engaging in and sharing their own teacher inquiries have the potential to support the practice. Such conditions may create safe spaces for teachers to take risks by inquiring into their teaching practices and to honestly share successes and failures with colleagues. At the end of the study we acknowledge the complexity of sustaining teacher inquiry as a professional learning practice, particularly as participants identified that there was always something new to take up, and never enough time.

\section{Concluding Thoughts}

The role of administration and leaders within a school community cannot be underestimated in establishing the necessary trust needed for teachers to engage in teacher inquiry. Participants indicated that they were interested in engaging in the teacher inquiry process but needed to feel trusted by their administration as well as their colleagues to do so. Establishing trust in multiple ways seems necessary for teacher inquiry, so teachers can authentically engage in the process. Participants felt that administrators held the power to make this happen, particularly if they lead by example. Trust amongst colleagues is also important, so that sharing in honest dialogue and risk-taking may inform a school professional learning culture that embraces inquiry as stance (Cochran-Smith \& Lytle, 2009).

\footnotetext{
1 All names are pseudonyms.

${ }^{2}$ Congeniality refers to the ability of people to work with each other in a friendly manner, though does not ensure achievement of goals or growth of practice

${ }^{3}$ Collegiality refers to the ability of people to willingly work with each other towards a common goal, through ongoing dialogue and growth of practice.
} 


\section{References}

Applefield, J. M., Huber, R., \& Moallem, M. (2001). Constructivism in theory and practice: Toward a better understanding. The High School Journal, 84(2), 35-53.

Birenbaum, M., Kimron, H., \& Shilton, H. (2011). Nested contexts that shape assessment "for" learning: School-based professional learning community and classroom culture. Studies in Educational Evaluation, 37(1), 35-48.

Birenbaum, M., Kimron, H., Shilton, H., \& Shahaf-Barzilay, R. (2009). Cycles of inquiry: Formative assessment in service of learning in classrooms and in school-based professional communities. Studies in Educational Evaluation, 35(4), 130-149.

Borg, S. (2010). Language teacher research engagement. Language Teaching, 43(4), 391-429. doi: $10.1017 / \mathrm{S} 0261444810000170$

Butt, I. H., \& Shams, J. A. (2013). Master in education student attitudes towards research: A comparison between two public sector universities in Punjab. South Asian Studies, 28(1), 97-105.

Castle, K. (2006). Autonomy through pedagogical research. Teaching and Teacher Education: An International Journal of Research and Studies, 22(8), 1094-1103.

Cochran-Smith, M., \& Lytle, S. L. (1992). Communities for teacher research: Fringe or forefront? American Journal of Education, 100(3), 298.

Cochran-Smith, M., \& Lytle, S. L. (2009). Inquiry as stance: Practitioner research for the next generation. New York, NY: Teachers College Press.

Cochran-Smith, M., \& Boston College Evidence Team. (2009). "Re-culturing" teacher education: Inquiry, evidence and action. Journal of Teacher Education, 60(5), 458-468.

Cooper, B., \& Cowie, B. (2010). Collaborative research for assessment for learning. Teaching and Teacher Education, 26, 979-986.

Darling-Hammond, L., \& McLaughlin, M. W. (1995). Policies that support professional development in an era of reform. Phi Delta Kappan, 76(8), 597-604.

Delamont, S., \& Atkinson, P. (1980). The two traditions in educational ethnography: Sociology and anthropology compared. British Journal of Sociology of Education, 1(2), 139-152.

Ellis, C., \& Castle, K. (2010). Teacher research as continuous process improvement. Quality Assurance in Education, 18(4), 271-285. doi: 10.1108/09684881011079134

Ermeling, B. A. (2009). Tracing the effects of teacher inquiry on classroom practice. Teaching and Teacher Education, 26(3), 377-388.

Esposito, J., \& Smith, S. (2006). From reluctant teacher to empowered teacher-researcher: One educator's journey toward action research. Teacher Education Quarterly, 33(3), 45-60.

Fichtman Dana, N., \& Yendol-Hoppey, D. (2014). The reflective educator's guide to classroom research: Learning to teach and teaching to learn through practitioner inquiry $\left(3^{\text {rd }} \mathrm{ed}\right.$.). Thousand Oaks, CA: Corwin Press. 
Geertz, C. (1973). The interpretation of cultures. New York, NY: Basic Books.

Hallam, P. R., Smith, H. R., Hite, J. M., Hite, S. J., \& Wilcox, B. R. (2015). Trust and collaboration in PLC teams: Teacher relationships, principal support, and collaborative benefits. NASSP Bulletin, 99(3), 193-216.

Hammersley, M. (2006). Ethnography: Problems and prospects. Ethnography and Education, 1(1), 3-14. doi: 10.1080/17457820500512697

Harrison, C. (2013). Collaborative action research as a tool for generating formative feedback on teachers' classroom assessment practice: The KREST project. Teachers and Teaching: Theory and Practice, 19(2), 202-213.

Hulburt, K.J., \& Knotts, M. (2012). Making the turn: Fostering an inquiry stance in teacher education. English Teaching: Practice and Critique, 11(2), 94-112.

Jao, L., \& McDougall, D. (2015). The collaborative teacher inquiry project: A purposeful professional development initiative. Canadian Journal of Education, 38(1), 1-22.

Kelly, J., \& Cherkowski, S. (2015). Collaboration, collegiality, and collective reflection: A case study of professional development for teachers. Canadian Journal of Educational Administration and Policy, 169, 1-27.

Latta, M. M., \& Kim, J. (2010). Narrative inquiry invites professional development: Educators claim the creative space of praxis. The Journal of Educational Research, 103(2), 137-148.

Lankshear, C., \& Knobel. M. (2004). A handbook for teacher research: From design to implementation. Berkshire, UK: Open University Press.

LeCompte, M. D., \& Goetz, J. P. (1982). Problems of reliability and validity in ethnographic research. Review of Educational Research, 52(1), 31-60.

Limbrick, L., Buchanan, P., Goodwin, M., \& Schwarcz, H. (2010). Doing things differently: The outcomes of teachers researching their own practice in teaching writing. Canadian Journal of Education, 33(4), 897-924.

Lytle, S. L., \& Cochran-Smith, M. (1992). Teacher research as a way of knowing. Harvard Educational Review, 62(4), 447-474.

Merriam, S. B., \& Tisell, E. J. (2016). Qualitative research: A guide to design and implementation ( $4^{\text {th }}$ ed.). San Francisco, CA: Jossey-Bass.

Mitton-Kükner, J. (2013). Emerging critical literacy in teachers as novice researchers. Australian Journal of Teacher Education, 38(3), Article 1. 1-26. Available at:

http://ro.ecu.edu.au/ajte/vol38/iss3/1.

Mitton Kükner, J. (2014). Seeking time within time: Exploring the temporal constraints of women teachers' experiences as graduate students and novice researchers. McGill Journal of Education, 49(2), 459-478. 
Mitton Kukner, J. (2015a). Problematizing the benefits and challenges of teacher research: Burrowing into female teachers' temporal constraints experienced in the midst of the research process. LEARNing Landscapes, 8(2), 261-283.

Mitton Kukner, J. (2015b). Time constraints experienced by female teacher researchers in Canada and Turkey: Challenges to developing an autonomous professional learning mindset. Professional Development in Education, 42(4), 628-646. doi: 10.1080/19415257.2015.1073607.

Navaneedhan, C. G. (2011). Reflective teaching pedagogy as innovative approach in teacher education through open and distance learning. Journal of Media and Communication Studies, 3(12), 331-335.

Nelson, T. H., Deuel, A., Slavit, D., \& Kennedy, A. (2010). Leading deep conversations in collaborative inquiry groups. The Clearing House, 83(5), 175-179.

Patton, K., Parker, M., \& Neutzling, M. M. (2012). Tennis shoes required: The role of the facilitator in professional development. Research Quarterly for Exercise and Sport, 83(4), 522-32.

Pierides, D. (2010). Multi-sited ethnography and the field of educational research. Critical Studies in Education, 51(2), 179-195.

Roulston, K., Legette, R., Deloach, M., \& Pitman, C. B. (2005). What is "research" for teacherresearchers? Educational Action Research, 13(2), 169-190.

Simon, R. (2015). "I'm fighting my fight, and I'm not alone anymore": The influence of communities of inquiry. English Education, 48(1), 41-71.

Stenhouse, L. (1981). What counts as research? British Journal of Educational Studies, 29(2), 103-114.

Timperley, H. S., Parr, J. M., \& Bertanees, C. (2009). Promoting professional inquiry for improved outcomes for students in New Zealand. Professional Development in Education, $35(2), 227-245$.

Wilson, W. J., \& Chaddha, A. (2010). The role of theory in ethnographic research. Ethnography, 10(4), 549-564.

Yon, D. A. (2003). Highlights overviews of the history of educational ethnography. Annual Review of Anthropology, 32, 411-430.

Zeichner, K. M. (2003) Teacher research as professional development for P-12 educators in the USA. Educational Action Research, 11:2, 301-326. doi:10.1080/09650790300200211 